\title{
The influence of solar variability and the quasi-biennial oscillation on lower atmospheric temperatures and sea level pressure
}

\author{
I. Roy and J. D. Haigh \\ Blackett Laboratory, Imperial College London, London, UK \\ Received: 9 November 2010 - Published in Atmos. Chem. Phys. Discuss.: 14 December 2010 \\ Revised: 18 October 2011 - Accepted: 12 November 2011 - Published: 22 November 2011
}

\begin{abstract}
Our fundamental aim is to investigate solar cycle signals in sea level pressure. In order to see if these may relate, especially at high latitudes, to the solar influence on the stratosphere we start by investigating the temperature of the winter polar stratosphere and its dependence on the state of the Sun and the phase of the Quasi-Biennial Oscillation (QBO). We find that the choice of pressure level used to define the phase of the QBO is important in determining how the solar and QBO influences appear to act in combination.

Informed by this we carry out a multiple linear regression analysis of zonal mean temperatures throughout the lower stratosphere and troposphere. A combined solar*QBO temporal index exhibits strongly in the lower stratosphere, but in much of the troposphere any influence of the QBO, either on its own or coupled to solar effects is much smaller than the pure solar signal.
\end{abstract}

We use a similar approach to analyse sea level pressure (SLP) data, first using a standard QBO time series dating back to 1953 . We find at high latitudes that individually the solar and QBO signals are weak but that the compound solar*QBO temporal index shows a significant signal. This is such that combinations of low solar activity with westerly QBO and high solar activity with easterly QBO are both associated with a strengthening in the polar modes; while the opposite combinations coincide with a weakening. By employing a QBO dataset reconstructed back to 1900, we extend the SLP analysis back to that date and also find a robust signal in the surface SAM; though weaker for surface NAM.

Our results suggest that solar variability, modulated by the phase of QBO, influences zonal mean temperatures at high latitudes in the lower stratosphere, in the mid-latitude troposphere and sea level pressure near the poles. Thus a knowl-

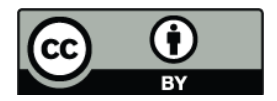

Correspondence to: I. Roy (indrani_r@hotmail.com) edge of the state of the Sun, and the phase of the QBO might be useful in surface climate prediction.

\section{Introduction}

There is an established body of literature (see Gray et al. (2010) for a review), initiated by the pioneering work of Labitzke (1987), which has identified the influence on winter temperatures in the polar lower stratosphere of the quasibiennial oscillation (QBO) in tropical lower stratospheric winds, and of solar activity (measured by sunspot number or some other indicator such as $10.7 \mathrm{~cm}$ radio flux). What these studies found was that by segregating the meteorological data by the phase of the QBO a clear signal of the 11-yr solar cycle was revealed. More specifically, that the JanuaryFebruary temperature at $30 \mathrm{hPa}$ over the North Pole tends to be warmer during the west phase of the QBO at high solar activity (HW) and also during the east phase at low solar activity (LE). Consistently, cold polar temperatures occur during LW and HE (Labitzke and van Loon, 1987, 1992; henceforth LvL), although the latter signal is weaker (Labitzke et al., 2006; henceforth LKB06) and its statistical robustness has been challenged (Camp and Tung, 2007; henceforth CT07). Another way of viewing this result (Gray et al., 2004; Naito and Hirota, 1997) is that the so-called Holton Tan effect (Holton and Tan, 1980, 1982), in which polar temperatures are colder during $\mathrm{wQBO}$ than $\mathrm{eQBO}$, is only effective when the Sun is less active.

In performing such analyses choices need to be made regarding the polar temperature data (choice of months and pressure levels) and the thresholds used to determine the phase of the QBO (choice of pressure level) and the state of the Sun (choice of high/low activity values). There are no "correct" choices but comparison between the conclusions

Published by Copernicus Publications on behalf of the European Geosciences Union. 
Table 1. Choice by different authors of various parameters used in studies of the influence of solar variability and the QBO on Northern Hemisphere winter polar temperatures.

\begin{tabular}{lccc}
\hline Parameter & LvL & LKB06 & CT07 \\
\hline Pressure level for temperature $(\mathrm{hPa})$ & 30 & 30 & $10-50$ \\
Month(s) for temperature & $\mathrm{JF}$ & $\mathrm{F}$ & $\mathrm{FM}$ \\
Thresholds for solar min/max $(\mathrm{F} 10.7$ index/10) & $<160 />160$ & $<110 />150$ & $<125 />140$ \\
Pressure level for QBO phase (hPa) & 40,50 & 45 & 30 \\
\hline
\end{tabular}

of different studies can be confused by the use of different values. Examples of the choices made in three important works are given in Table 1. Using these СT07 found that, while their results concurred with LvL in that $\mathrm{LW}$ emerged as distinctly cold, the temperatures of the other three (all warmer) groupings were statistically indistinguishable from each other. To inform an understanding of polar temperature variability, and to provide a test for model results, it is clearly important that the solar and QBO influences are properly characterised. Thus there is a need to understand the influences on results and conclusions introduced by the use of different factors.

The choice of altitude for the temperature measurement affects results: LKB06 show that at the winter North pole the magnitude of the solar signal declines at levels above about $50 \mathrm{hPa}$ and during eQBO the sign changes at pressures less than about $25 \mathrm{hPa}$. Thus the choice of a $10-50 \mathrm{hPa}$ average, such as used by CT07, will give a smaller signal than of $30 \mathrm{hPa}$, as LvL, especially during eQBO. Similarly the dates chosen have an impact: LKB06 state that the largest signal is found in February. We find (results not presented here) that the JF signal is larger than that in FM. Again the choice of FM by CT07 will lead to a smaller signal than found in the comparison papers.

Variations in strength of the winter stratospheric polar vortex are typically followed, with a lag of less than one month, by similar-signed anomalies in the tropospheric circulation that persist for up to 2 months in the Northern Hemisphere and up to 3 months in the Southern (Thompson and Wallace 2000; Baldwin and Dunkerton, 2001). Other studies have shown that in the Northern Hemisphere winter extratropics a solar signal in polar winter temperature and wind is QBOphase dependent, moving poleward and downward as winter progresses, taking about 1 month to move from the upper to the lower stratosphere with a faster descent rate under wQBO than eQBO (Matthes et al., 2004; Gray et al., 2004; Lu et al., 2009; Haigh and Roscoe, 2009) showed a similar progression in the Southern Hemisphere late winter.

These studies are consistent with the results found in surface polar modes (Northern Annular Mode, NAM, and Southern Annular Mode, SAM) by Haigh and Roscoe (2006) which indicated that, while no statistically significant solar signal was found in either the surface NAM or SAM, when the solar and QBO influences were combined there is a good correlation in SAM and winter NAM. The combined effect was represented by a single time series (subsequently referred to as solar*QBO) which incorporated the change of sign in the QBO depending on solar activity, consistent with LvL. Further details of this follow in the next section.

In this paper we first investigate the influence of the choice of QBO pressure level threshold on an LvL-like analysis of northern winter polar temperatures. Informed by that study we then investigate the combined solar* $\mathrm{QBO}$ influence on zonal mean temperature throughout the stratosphere and troposphere. We move on to study signals of solar variability and the QBO in over a century of mean sea level pressure (SLP) data.

\section{Data}

\subsection{Data analysed}

The temperature data are taken from the NCEP-NCAR Reanalysis Project Kalnay et al. (1996) for the years 19532004. For the polar temperature analysis we use JanuaryFebruary mean values at $30 \mathrm{hPa}$ omitting those years strongly affected by volcanic eruptions $(1964,1983,1992)$. For the latitude-height sections we use monthly mean data throughout the year.

The mean sea level pressure data, obtained from http: //www.hadobs.org, are globally gridded monthly mean values for 1900-2004 from the HadSLP2 dataset, an upgraded version of the Hadley Centre's monthly historical set which is based on a compilation of numerous terrestrial and marine data (Allan and Ansell, 2006).

\subsection{Influencing factors}

We assess the influence of a number of independent influences on the temperature and SLP data. These include, solar variability and the phase of the QBO, "climate change", stratospheric aerosol and the phase of the El Niño-Southern Oscillation (ENSO) (see Fig. 1).

We specify a linear trend to represent long term climate change. This cover-all essentially incorporates greenhouse gases, tropospheric aerosol, stratospheric ozone and 

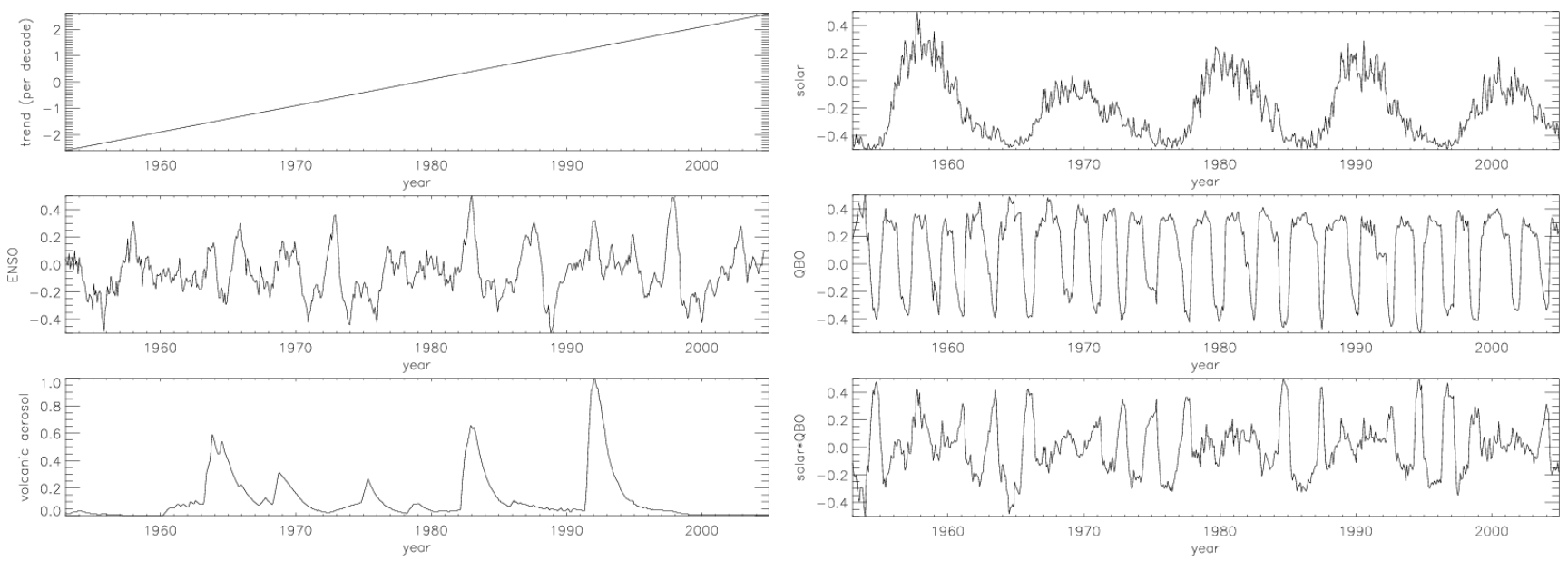

Fig. 1. Time series used in the multiple regression. From the top: linear trend (per decade); normalised ENSO index; normalised stratospheric aerosol index; normalised sunspot number; normalised QBO $(40 \mathrm{hPa})$ index; compound solar*QBO index. The regression analysis uses either the solar and QBO indices or the compound index. After Haigh and Roscoe (2006).

long-term changes in the Sun. Secular variation in solar irradiance is currently the subject of significant uncertainty and, furthermore, the focus of our work is on 11-yr cycle variability so that the choice of long-term trend has essentially no effect on the derived solar signal.

Solar cycle variability is represented either by radio flux (F10.7 index), specifically for comparison with the LvL and CT07 studies, or by monthly mean sunspot number (SSN), where values before 1957 are required. Both these datasets are acquired from the NOAA National Geophysical Data Center Solar and Terrestrial Physics Division http://www. ngdc.noaa.gov/stp/.

Aerosols injected into the stratosphere by explosive volcanic eruptions impact both stratospheric and tropospheric temperatures (Solomon et al., 2007). Here we represent the temporal variation of their effect using a measure of stratospheric aerosol optical depth (AOD) from http://data. giss.nasa.gov/modelforce/strataer/tau_line.txt for years up to 1999, extended to 2005 with near zero values.

For ENSO, we used the Niño 3.4 index, obtained from http://climexp.knmi.nl, defined as the three month running mean of sea surface temperature departures in the Niño 3.4 region $\left(5^{\circ} \mathrm{N}-5^{\circ} \mathrm{S}, 120-170^{\circ} \mathrm{W}\right)$, calculated with respect to the 1971-2000 base period.

Since 1953 the stratospheric research group at the Free University Berlin has collected and processed rawinsonde measurements from Canton Island, Gan (Maldives) and Singapore (Naujokat, 1986; Labitzke, 2002). These data, showing the phase of the QBO as it descends from $10 \mathrm{hPa}$ to $70 \mathrm{hPa}$, are available from http://www.pa.op.dlr.de/CCMVal/ Forcings/qbo_data_ccmval/u_profile_195301-200412.html. Recently a QBO time series extending back to 1900 has been reconstructed by Brönnimann et al. (2007) (henceforth BAVJ07). This is based on historical pilot balloon data as well as hourly sea-level pressure data from Jakarta, Indonesia. The latter were used to extract the signal of the solar semi-diurnal tide in the middle atmosphere, which is modulated by the QBO. The reconstructions are in good agreement with the QBO signal extracted from historical total ozone data extending back to 1924 .

The QBO propagates downward with a speed of approximately $1 \mathrm{~km} /$ month with a full cycle taking about 28 months. Thus the phase ascribed to it is a function of altitude (pressure) and the results of studies which assess its influence on other meteorological variables may be sensitive to the choice of QBO pressure level.

The compound solar*QBO index (Haigh and Roscoe, 2006 ) is a product of the normalised solar and QBO indices such that the QBO series is inverted when the Sun is below mean activity (see bottom panel of Fig. 1). A similar approach (referred to as "LvL modulation") had been used earlier by Dunkerton and Baldwin (1992). Thus the LE and HW have positive values, while LW and HE have negative. Note, however, that because SSN returns essentially to zero at every solar cycle minimum but that its value at solar maximum is very variable, the $\mathrm{QBO}$ signal has much larger amplitude at solar minimum than solar maximum. This then mirrors well the weaker QBO signal in polar temperatures found by both $\mathrm{LvL}$ and CT07. The solar* $\mathrm{QBO}$ has been used effectively by Roscoe and Haigh (2006) and Haigh and Roscoe (2009) to investigate signals in polar modes and by Camargo and Sobel (2010) for tropical cyclones. Note that the regression analysis uses either the combined index or the separate solar and QBO indices so that there is no cross-dependence of the indices and no non-linearity. 
Table 2. Mean JF temperature of the polar stratosphere at $30 \mathrm{hPa}$ sorted by low/high solar activity (defined by values of F10.7 of $</>155$ units) and QBO phase determined by the sign of the zonal wind over the equator at the given pressure levels. Also given in each segment are the standard deviation of the temperature data and number of data points.

\begin{tabular}{clrrrrrr}
\hline QBO pressure $(\mathrm{hPa})$ & & LW & HE & LE & HW & LW\&HE & LE\&HW \\
\hline \multirow{2}{*}{20} & mean $T$ & 204.1 & 207.0 & 203.5 & 206.2 & 205.3 & 204.1 \\
& std dev & 7.5 & 6.6 & 6.3 & 5.7 & 7.3 & 6.2 \\
& $n$ & 14 & 11 & 15 & 5 & 25 & 20 \\
\hline \multirow{2}{*}{30} & mean $T$ & 202.7 & 207.7 & 204.7 & 205.5 & 204.8 & 205.0 \\
& std dev & 7.0 & 6.3 & 6.7 & 6.3 & 7.1 & 6.6 \\
& $n$ & 14 & 10 & 14 & 7 & 24 & 21 \\
\hline \multirow{2}{*}{40} & mean $T$ & 200.6 & 204.2 & 207.7 & 208.7 & 201.7 & 208.1 \\
& std dev & 5.2 & 5.4 & 6.6 & 6.3 & 5.5 & 6.5 \\
& $n$ & 16 & 7 & 13 & 9 & 23 & 22 \\
\hline 45 & mean $T$ & 200.5 & 203.4 & 207.8 & 208.8 & 201.3 & 208.2 \\
& std dev & 5.2 & 5.4 & 6.5 & 5.9 & 5.4 & 6.3 \\
& $n$ & 16 & 6 & 13 & 10 & 22 & 23 \\
\hline \multirow{2}{*}{50} & mean $T$ & 201.6 & 203.4 & 207.3 & 208.8 & 202.1 & 208.0 \\
& std dev & 6.5 & 5.4 & 6.0 & 5.9 & 6.3 & 6.0 \\
& $n$ & 18 & 6 & 11 & 10 & 24 & 21 \\
\hline & mean $T$ & 201.5 & 203.4 & 207.0 & 208.8 & 202.0 & 207.8 \\
& std dev & 6.5 & 5.4 & 6.1 & 5.9 & 6.2 & 6.1 \\
& $n$ & 17 & 6 & 12 & 10 & 23 & 22 \\
\hline \multirow{2}{*}{60} & mean $T$ & 201.8 & 204.2 & 206.6 & 208.3 & 202.4 & 207.4 \\
& std dev & 6.7 & 5.9 & 6.1 & 6.1 & 6.6 & 6.2 \\
& $n$ & 17 & 6 & 12 & 10 & 23 & 22 \\
\hline & & & & & & &
\end{tabular}

\section{North pole winter lower stratosphere temperature}

In order to diagnose the impact of the choice of different parameters in determining the relationships between solar and QBO variability and polar temperature we have carried out a number of tests using the range of parameters shown in Table 1 . We find that the greatest sensitivity is to choice of QBO altitude. The results presented below all use JF polar temperature at $30 \mathrm{hPa}$, for the reasons outlined above.

We start by sorting the temperature data into four groupings by whether at the date in question the $\mathrm{F} 10.7 \mathrm{~cm}$ index is less than/greater than 155 units and the QBO index at a prescribed pressure level is less than/greater than zero. We calculate the average value of all the temperature values which fall within the respective quadrant. The results are presented in Table 2 for different choices of QBO pressure. Also shown in Table 2 are the same temperature data sorted into two groupings as suggested by the LvL analysis, viz LW together with HE and LE with HW.

Table 3 presents the differences in temperature between the various groupings, together with indications of the statistical significance of these differences. These show for all QBOs in the $40-70 \mathrm{hPa}$ range that $\mathrm{LW}$ is always the coldest quadrant and HE the second coldest; these two states are not statistically distinguishable. Similarly in this pressure range HW is always the warmest and LE the second warmest with the values not statistically different. The differences (HWLW, LE-LW, HW-HE, LE-HE) are all positive, consistent with the LvL conclusions. At the $40-70 \mathrm{hPa}$ pressure levels all the differences are statistically significant at at least the $90 \%$ level (and generally higher) except the slightly smaller values for $\mathrm{LE}-\mathrm{HE}$. With a higher number of samples (than LE - HE) the (LE \& HW) - HE difference does become significant at the $90 \%$ level. Whilst the (LE + HW) - LW significance levels are larger than those for $(\mathrm{LE}+\mathrm{HW})-\mathrm{HE}$ the lack of any signficant difference between LW and HE encourages us to follow LvL and group LW and HE together. Indeed the difference between $(\mathrm{LE}+\mathrm{HW})-(\mathrm{LW}+\mathrm{HE})$ is highly significant, clearly demonstrating the LvL effect.

At higher QBO altitudes the pattern changes: at $30 \mathrm{hPa}$ $\mathrm{LW}$ is still coldest but HE is now warmest. This is consistent with the results of CT07 who found, using the $30 \mathrm{hPa}$ QBO that, while LW emerged as distinctly cold, the temperatures of the other three (all warmer) groupings were statistically indistinguishable from each other. Thus the LvL effect is not present at the higher QBO altitudes. Note that our results do not directly correspond to those of CT07 because of the use 
Table 3. Difference in temperature between the groupings presented in Table 2. Values estimated to be significant at the [90, 95, 99] \% level are given in [underlined; bold; bold and underlined] type.

\begin{tabular}{|c|c|c|c|c|c|c|c|c|c|}
\hline $\begin{array}{c}\text { QBO pressure } \\
(\mathrm{hPa})\end{array}$ & $\begin{array}{r}\text { LE- } \\
\text { LW }\end{array}$ & $\begin{array}{r}\text { HW- } \\
\text { HE }\end{array}$ & $\begin{array}{r}\text { LE- } \\
\text { HE }\end{array}$ & $\begin{array}{l}\text { HW- } \\
\text { LW }\end{array}$ & $\begin{array}{r}\mathrm{HE}- \\
\mathrm{LW}\end{array}$ & $\begin{array}{r}\text { HW- } \\
\text { LE }\end{array}$ & $\begin{array}{r}(\mathrm{LE} \& \mathrm{HW})- \\
\mathrm{LW}\end{array}$ & $\begin{array}{r}(\mathrm{LE} \& \mathrm{HW})- \\
\mathrm{HE}\end{array}$ & $\begin{array}{r}\text { (LE\&HW)- } \\
(\text { LW\&HE) }\end{array}$ \\
\hline 20 & -0.6 & -0.8 & -3.5 & 2.1 & 2.9 & 2.7 & 0.1 & -2.8 & -1.2 \\
\hline 30 & 2.0 & -2.2 & -3.0 & 2.7 & $\underline{5.0}$ & 0.8 & 2.2 & -2.7 & 0.2 \\
\hline 40 & 7.1 & 4.5 & 3.4 & $\underline{8.1}$ & $\overline{3.6}$ & 1.1 & 7.5 & 3.9 & $\underline{6.4}$ \\
\hline 45 & 7.3 & $\underline{5.4}$ & 4.4 & $\underline{8.3}$ & 2.9 & 1.0 & 7.7 & $\underline{4.8}$ & $\underline{6.9}$ \\
\hline 50 & 5.6 & 5.4 & 3.9 & $\overline{7.1}$ & 1.7 & 1.5 & 6.4 & $\underline{4.6}$ & $\underline{5.9}$ \\
\hline 60 & 5.5 & 5.4 & 3.6 & 7.3 & 1.9 & 1.7 & 6.3 & 4.4 & 5.8 \\
\hline 70 & 4.8 & $\overline{4.1}$ & 2.4 & 6.5 & 2.4 & 1.7 & $\underline{5.6}$ & 3.2 & 5.0 \\
\hline
\end{tabular}

of different altitudes and months for the temperature data, as discussed above. Another difference is the value chosen to differentiate low from high solar activity. In the results presented above we used 155 solar units as a threshold, similar to Labitzke and van Loon (1992), chosen for being the midrange value. We have repeated the analysis using the solar thresholds of CT07 (see Table 1) which has the effect of reclassifying $5 \mathrm{yr}$ from LS to HS and of removing 2 other LS years. The results are qualitatively similar to those using the 155 unit threshold, with the same signs as those presented in Table 2, but with mainly smaller magnitudes and thus weaker significance levels.

We conclude that the LvL pattern, viz opposite responses in winter polar lower stratospheric temperature to QBO phases during periods of high and low solar activity, is robust but is weakened by the use of each of:

- a higher altitude for the temperature data,

- temperatures during later winter months,

- a lower solar threshold,

- a higher altitude to define the QBO phase.

It is interesting to note that as the QBO-W signal propagates down through the stratosphere it often stalls between 30 and $50 \mathrm{hPa}$ so that the regions above and below are out of phase for several months. The EOF analysis mentioned in the previous section also found that the signals near 20-30 and $40-50 \mathrm{hPa}$ were, on average, out of phase. Thus sorting the temperature data according to the dates of these signals is likely to give different results. If the physical mechanisms which link tropical winds with polar temperatures are to be identified then the precise dating of the signals is essential.

In the following section we look at how the effects of the Sun and the QBO, separately and advised by the LvL effect in combination, influence zonal mean temperatures throughout the lower stratosphere and troposphere, with a focus on relationship with the polar lower stratosphere.

\section{Zonal mean temperatures}

We have analysed monthly mean zonal mean temperatures from 1953-2004 from the NCEP Reanalysis dataset (Kalnay et al., 1996) using the same multiple linear regression technique as Haigh (2003). This estimates amplitudes of variability due to various climate factors incorporating an autoregressive noise model. In this methodology, noise coefficients are calculated iteratively with the components of variability so that the residual is consistent with a red noise model of order one $(A R(1))$. We find by experiment with the monthly mean data that using a noise model of higher order does not significantly affect the results. A Student's t-test is used to estimate the level of confidence in the derived regression coefficients.

The regression uses the indices outlined in Sect. 2.2. We adopt two different approaches to the solar and QBO influences: the first includes separate indices for each (see panels 4 and 5 of Fig. 1) while the second uses the single compound index (panel 6 of Fig. 1).

Results using the first approach are shown in Fig. 2a for the solar signal and panel $b$ for the QBO. These are similar to those found previously by Haigh (2003) and Frame and Gray (2010). The solar signal is positive everywhere except in the polar lower stratosphere, statistically significant at the $5 \%$ level in mid-latitudes at all levels from the surface to $>25 \mathrm{~km}$ and largest $(>0.75 \mathrm{~K})$ in the lower stratosphere sub-tropics with lobes of about $0.5 \mathrm{~K}$ extending into tropospheric mid-latitudes. The QBO signal has its characteristic, and strong, butterfly pattern in the low latitude stratosphere with a cooling in the polar stratosphere and little impact on the troposphere.

The second approach, using the combined index, is shown in Fig. 2c. The Northern Hemisphere polar lower stratosphere signal is positive, as would be expected from the $\mathrm{LvL}$ results, but does not appear in the Southern Hemisphere. The positive signal extends to the surface in mid-latitudes but is smaller than the solar impact alone in the troposphere. The warmer Southern high latitude troposphere is consistent with 


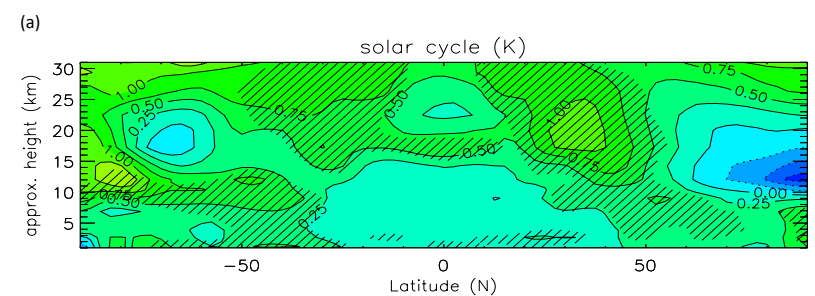

(b)

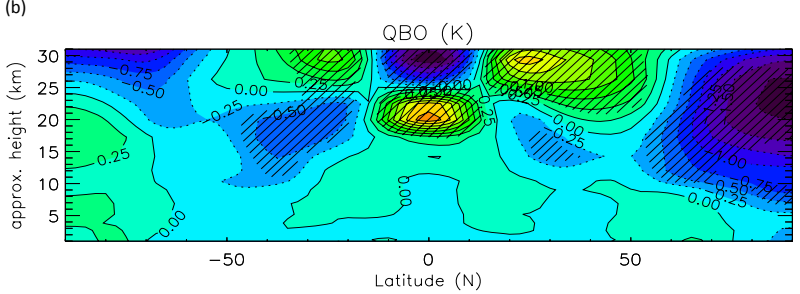

(c)

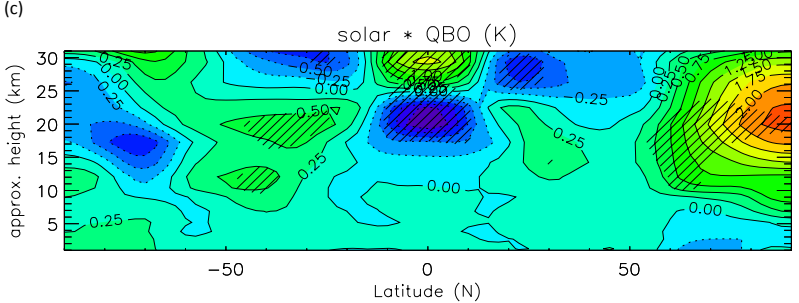

Fig. 2. Results from multiple linear regression analysis of NCEP reanalysis zonal mean monthly mean temperatures (1958-2004). (a) and (b) show the signals associated with solar variability and the QBO, respectively, when these are included as independent indices in a multiple regression. (c) shows the results of a different analysis in which the compound index is used in place of the two individually. The contour interval is $0.25 \mathrm{~K}$; positive values have solid lines and green-red colouring, negative values dashed lines and blue-black; hatching indicates a signal ascertained to be statistically significant at the $5 \%$ level.

the Haigh and Roscoe (2009) results for SAM. Thus using the compound index suggests a weak relationship between the polar lower stratosphere and mid-latitude troposphere in the Northern Hemisphere and a stronger one between the extra-tropical lower stratosphere and lower troposphere high latitude temperatures in the Southern Hemisphere. The compound index is not helpful in understanding correlations in the tropics.

\section{Sea level pressure}

Previous studies (Baldwin and Dunkerton, 1999, 2001, 2005; Thompson et al., 2005) have shown that large-amplitude variations in the strength of the stratospheric polar vortex are typically followed, with a lag of less than one month, by similar signed anomalies in the tropospheric circulation. These can persist for up to 2-3 months and suggest a route whereby changes in stratospheric circulation may influence surface climate and Baldwin and Dunkerton (2005) suggested that solar and QBO influences may be felt at the surface via the annular modes. We now investigate solar and QBO signals in sea level pressure to see if these are consistent with this idea and our results above.

\section{$5.1 \quad 1953-2004$}

A multiple regression analysis of the SLP data are has been carried out, similar to that of Roy and Haigh (2010) except that it incorporates an assessment of the QBO signal. The latter is investigated using both of the approaches as for the zonal mean temperature, viz. separate solar and QBO indices or the combined index. Because direct measurements of QBO phase are only available back to 1953 our first analysis uses data only since that date. The independent parameters used are: a linear trend, AOD, SSN, ENSO, QBO at $30 \mathrm{hPa}$ and QBO at $50 \mathrm{hPa}$. Some of the results are shown in Fig. 3. The solar signal (Fig. 3a) shows positive values in the tropics and negative ones in mid latitudes, with a significant negative anomaly in the South Pacific. Moreover, the pattern shows positive values on the poleward sides of the sub-tropical high pressure regions, suggesting an expansion of the tropical Hadley cells; first found as a solar signal in a GCM experiment by Haigh (1996). The largest signal is associated with ENSO (Fig. 3d), showing the longitudinal gradients in the Pacific Ocean characteristic of that phenomenon. QBO-50 (Fig. 3b) shows a small, but significant increase in pressure across much of the tropics. The QBO-30 pattern (not shown) shows a pattern with greatest impact in mid- to high latitudes, but very little of significance.

The results for polar temperatures in Sect. 3, for zonal mean temperatures in Sect. 4 and for SAM by Haigh and Roscoe (2009), all showed some stronger signals in response to a combined solar*QBO index than to either separately. We now carry out the regression analysis of the SLP data using this compound index (incorporating the QBO-50 series). Other indices used in the regression were the linear trend, AOD and ENSO. The resulting solar*QBO signal is shown in Fig. 3c. It indicates a weakening of the annular modes in the Northern and the Southern Hemispheres, thus it appears that the LE and HW combinations produce negative signals in surface SAM and NAM while the LW and HE combinations are associated with strengthening modes. A negative signal is seen over most of the tropics in both panels. The same analysis using the QBO-30 series in place of the QBO-50 (not shown) produces a similar pattern, although of smaller amplitude. We assume that the distinction between the responses to different QBO levels seen in the stratosphere is washed out as the signal propagates further downwards due to the variability in time it takes for the anomaly to reach the surface (Baldwin and Dunkerton, 1999). 
(a)

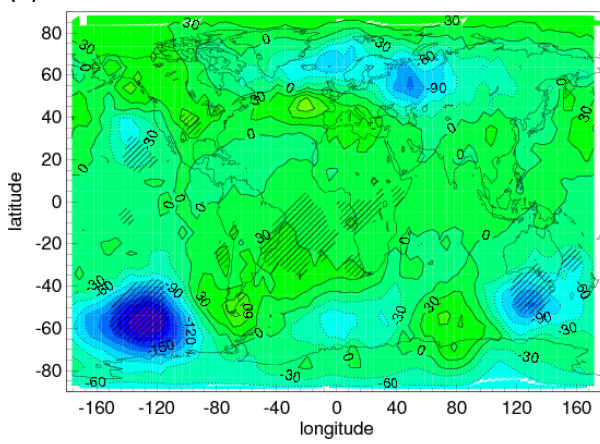

(c)

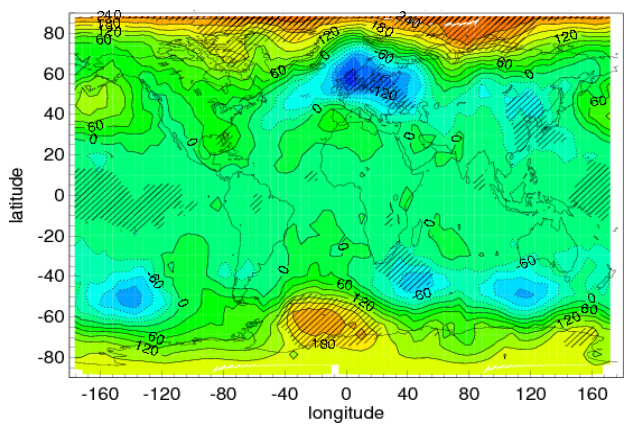

(b)

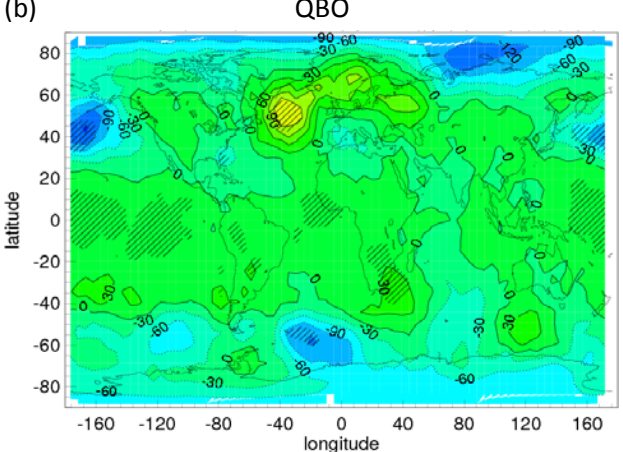

(d)

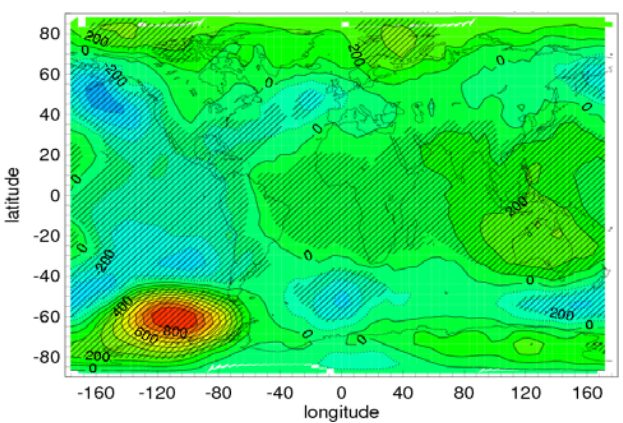

Fig. 3. Results of multiple linear regression analysis of sea level pressure data 1953-2004. Components (Pa) due to (a) Solar (SSN); (b) ENSO; (c) QBO (at $50 \mathrm{hPa}$ ) Results of a separate analysis in (d) show the compound Solar*QBO (at $50 \mathrm{hPa}$ ) signal. Dashed lines indicate negative values; hatching indicates areas assessed statistically significant at the $5 \%$ level. Contour interval in (a), (b) and (c) is $30 \mathrm{~Pa}$ and for (d) $100 \mathrm{~Pa}$. The same colours are used each side of the zero contour in all panels.

\section{$5.2 \quad 1900-2004$}

The availability of the BAVJ07 reconstruction of the QBO dating back to 1900 , discussed in Sect. 2.3, enables us to analyse the role of the QBO over a longer term climate record. First, as a consistency check, we carried out an analysis with these data for the period 1953-2004. The results (not shown) are similar to those derived using the DLR QBO data (and shown in Fig. 3) providing confidence in an extension to the analysis back through the earlier period.

Results from the analysis of the whole, more than a century, period are shown in Fig. 4. Comparison with the corresponding panels in Fig. 3 shows overall similar patterns, indicating that some responses are robust for over a century, but also some differences. The signals deemed statistically significant in the solar response in the Northern sub-tropics of the Pacific, Southern sub-tropics of the Atlantic and the Southern Ocean are largely maintained, or even strengthened over the longer period. The QBO pattern is retained, except very close to the North Pole and the Solar*QBO is strengthened almost everywhere except close to the North Pole.

\section{Summary and conclusions}

Our initial aim was to understand the reason(s) for an apparent inconsistency between published results concerning the temperature of the winter polar stratosphere and its dependence on the states of the Sun and the QBO. We show that some differences are introduced by use of different altitudes/months for the temperature data, of different thresholds to define high/low solar activity and, particularly, of different pressure levels to define the phase of the QBO. EOF analysis reveals that the QBO around $40-50 \mathrm{hPa}$ is, on average, temporally out of phase with that at $20-30 \mathrm{hPa}$ so that the use of these two levels by e.g. Labitzke and van Loon (1992) and Camp and Tung (2007), respectively, means that they are not seeing the same aspect of any physical signal. We note that none of these statistical studies provides any mechanism for the apparent relationships but that the different responses might indicate where causal links occur. For example, Gray et al. (2004) propose an effect of solar/QBO variability whereby a perturbation to the sub-tropical upper stratosphere might affect the polar lower stratosphere after 3-4 months through influencing the timing of sudden stratospheric warmings. Over this period the QBO phase would have descended 3-4 km in the tropics so that an instantaneous 
(a)

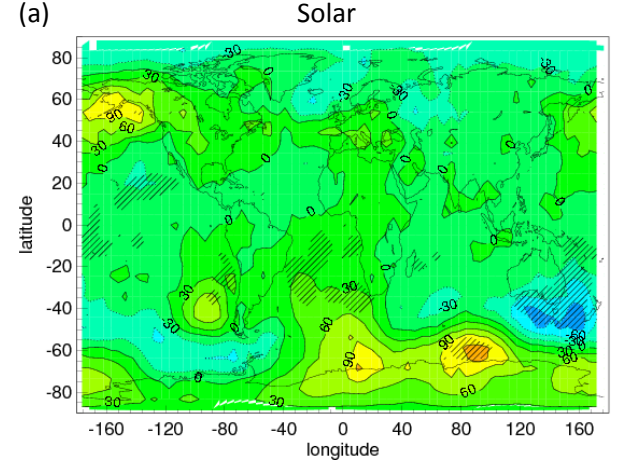

(c)

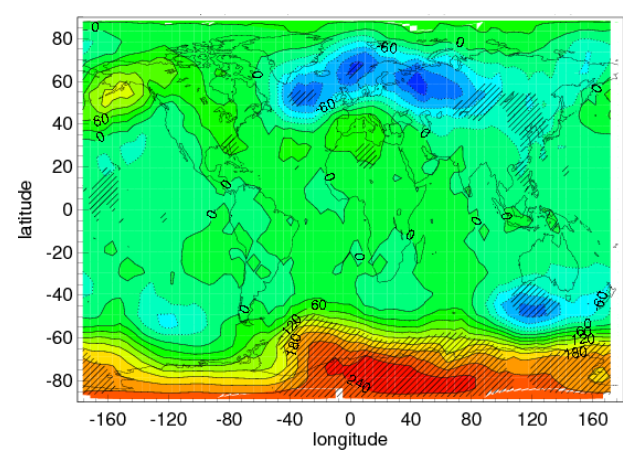

Solar*QBO (b)

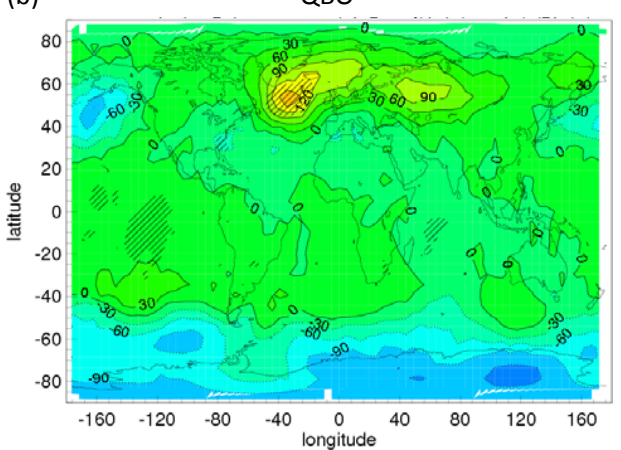

Fig. 4. Same as Fig. 3a, b and c respectively, but over the period 1900-2004, using the Brnnimann et al. (2007) QBO time series. The contour interval is $30 \mathrm{~Pa}$ and colours around the zero contour are same as Fig. 3.

correlation between polar temperature and QBO would appear highest at lower altitudes in the tropics.

We have also analysed zonal mean temperatures throughout the lower stratosphere and troposphere to investigate the existence more widely of any coupled solar and QBO influence. We find, while it exhibits strongly in the lower stratosphere, that in the troposphere any influence of the QBO, either on its own or coupled to solar effects is much smaller than the pure solar signal. A possible exception is manifest at very high latitudes with warmer temperatures corresponding to the LE and HW states (and colder to LW and HE).

Seeking to investigate further the solar and QBO influences at the surface we also carried out a multiple regression analysis of SLP data. First we accomplished this, using established QBO time series 1953-2004. By themselves the solar and QBO signals were rather weak, although the solar pattern is consistent with previous studies suggesting a slight expansion of the Hadley cells when the Sun is more active (Haigh, 1996; Haigh et al., 2005). The compound solar*QBO signal shows significant increase in SLP at very high latitudes, consistent with LW and HE produce a strengthening (and LE and HW a weakening) in the annular modes.
By employing a QBO dataset reconstructed back to 1900 we were able to extend our SLP analysis back to that date. We find a robust signal in the Southern Hemisphere, which shows a response in surface SAM as described above, independently in both the first and second half of the century. This result is found almost irrespective of details of the choice of QBO index pressure. The Northern Hemisphere result is qualitatively similar but smaller and less statistically robust.

We conclude that a signal of solar variability, modulated by the phase of the QBO, is detectable in sea level pressure at high latitudes and thus that a knowledge of the state of the Sun and of the QBO might be useful in predicting tendencies in polar surface climate on timescales of a few years.

Acknowledgements. IR was supported by a studentship from the UK Natural Environment Research Council; this work was partially funded by the NERC SOLCLI consortium grant. We are grateful to Myles Allen for provision of the multiple regression code.

Edited by: P. Haynes 


\section{References}

Allan, R. and Ansell, T.: A new globally complete monthly historical gridded mean sea level pressure dataset (HadSLP2): 18502004, J. Climate, 19, 5816-5842, 2006.

Baldwin, M. P. and Dunkerton, T. J.: Propagation of the Arctic Oscillation from the stratosphere to the troposphere, J. Geophys. Res.-Atmos., 104, 30937-30946, 1999.

Baldwin, M. P. and Dunkerton, T. J.: Stratospheric harbingers of anomalous weather regimes, Science, 294, 581-584, 2001.

Baldwin, M. P. and Dunkerton, T. J.: The solar cycle and stratosphere-troposphere dynamical coupling, J. Atmos. SolarTerr. Phys., 67, 71-82, 2005.

Brönnimann, S., Annis, J. L., Vogler, C., and Jones, P. D.: Reconstructing the quasi-biennial oscillation back to the early 1900s, Geophys. Res. Lett., 34, L22805, doi:10.1029/2007g1031354, 2007.

Camargo, S. J. and Sobel, A. H.: Revisiting the influence of the Quasi-Biennial Oscillation on tropical cyclone activity, J. Climate, 23, 5810-5825, 2010.

Camp, C. D. and Tung, K. K.: The influence of the solar cycle and QBO on the late-winter stratospheric polar vortex, J. Atmos. Sci., 64, 1267-1283, doi:10.1175/jas3883.1, 2007.

Dunkerton, T. J. and Baldwin, M. P.: Modes of interannual variability in the stratosphere, Geophys. Res. Lett., 19, 49-52, 1992.

Frame, T. H. A. and Gray, L. J.: The 11-Yr Solar Cycle in ERA-40 Data: An Update to 2008, J. Climate, 23, 2213-2222, doi:10.1175/2009jcli3150.1, 2010.

Gray, L. J., Crooks, S., Pascoe, C., Sparrow, S., and Palmer, M.: Solar and QBO influences on the timing of stratospheric sudden warmings, J. Atmos. Sci., 61, 2777-2796, 2004.

Gray, L. J., Beer, J., Geller, M., Haigh, J. D., Lockwood, M., Matthes, K., Cubasch, U., Fleitmann, D., Harrison, G., Hood, L., Luterbacher, J., Meehl, G. A., Shindell, D., van Geel, B., and White W.: Solar influences on climate, Rev. Geophys., 48, RG4001, doi:10.1029/2009RG000282, 2010.

Haigh, J. D.: The impact of solar variability on climate, Science, 272, 981-984, 1996.

Haigh, J. D.: The effects of solar variability on the Earth's climate, Philos. T. Roy. Soc. London Series a, 361, 95-111, 2003.

Haigh, J. D. and Roscoe, H. K.: Solar influences on polar modes of variability, Meteorol. Z., 15, 371-378, 2006.

Haigh, J. D. and Roscoe, H. K.: The Final Warming Date of the Antarctic Polar Vortex and Influences on its Interannual Variability, J. Climate, 22, 5809-5819, doi:10.1175/2009jcli2865.1, 2009.

Haigh, J. D., Blackburn, M., and Day, R.: The response of tropospheric circulation to perturbations in lower stratospheric temperature, J. Climate, 18, 3672-3685, 2005.

Holton, J. R. and Tan, H.-C..: The influence of the equatorial quasibiennial oscillation on the global circulation at $50 \mathrm{mb}$, J. Atmos. Sci., 37, 2200-2208, 1980.
Holton, J. R. and Tan, H.-C.: The quasi-biennial oscillation in the Northern Hemisphere lower stratosphere, J. Meteorol. Soc. Jpn, 60, 140-148, 1982.

Kalnay, E., Kanamitsu, M., Kistler, R., Collins, W., Deaven, D., Gandin, L., Iredell, M., Saha, S., White, G., Woollen, J., Zhu, Y., Chelliah, M., Ebisuzaki, W., Higgins, W., Janowiak, J., Mo, K. C., Ropelewski, C., Wang, J., Leetmaa, A., Reynolds, R., Jenne, R., and Joseph, D.: The NCEP/NCAR 40-year reanalysis project, B. Am. Meteorol. Soc., 77, 437-471, 1996.

Labitzke, K.: Sunspots, the QBO, and the stratopsheric temperature in the North polar-region, Geophys. Res. Lett., 14, 535-537, 1987.

Labitzke, K.: The Berlin stratospheric data series. Meteorological Institute, Free University of Berlin, CD-ROM, 2002.

Labitzke, K. and van Loon, H.: On the association between the QBO and the extratropical stratosphere, J. Atmos. Terr. Phys., 54, 1453-1463, 1992.

Labitzke, K., Kunzel, M., and Brönnimann, S.: Sunspots, the QBO and the stratosphere in the North Polar Region - 20 years later, Meteorol. Z., 15, 355-363, 2006.

Lu, H., Gray, L. J., Baldwin, M. P., and Jarvis, M. J.: Life cycle of the QBO-modulated 11-year solar cycle signals in the Northern Hemispheric winter, Q. J. Roy. Meteorol. Soc., 135, 1030-1043, doi:10.1002/qj.419, 2009.

Matthes, K. , Langematz, U., Gray, L., Kodera, K., and Labitzke, K.: Improved 11-year solar signal in the Freie Universitat Berlin Climate Middle Atmosphere Model (FUB-CMAM), J. Geophys. Res., 109, D06101, doi:10.1029/2003JD004012, 2004.

Naito, T. and Hirota, I..: Interannual variability of the Northern winter stratospheric circulation related to the QBO and the solar cycle, J. Meteorol. Soc. Jpn, 75, 925-937, 1997.

Naujokat, B.: An update of the observed quasi-biennial oscillation of the stratospheric winds over the tropics, J. Atmos. Sci., 43, 1873-1877, 1986.

Roy, I. and Haigh, J. D.: Solar cycle signals in sea level pressure and sea surface temperature, Atmos. Chem. Phys., 10, 3147-3153, doi:10.5194/acp-10-3147-2010, 2010.

Solomon, S., Qin, D., Manning, M., Chen, Z., Marquis, M., Averyt, K. B., Tignor, M., and Miller, H. L.: Contribution of Working Group I to the Fourth Assessment Report of the Intergovernmental Panel on Climate Change, 2007.

Thompson, D. W. J. and Wallace, J. M.: Annular modes in the extratropical circulation. Part I: Month-to-month variability, J. Climate, 13, 1000-1016, 2000.

Thompson, D. W. J., Baldwin, M. P., and Solomon, S.: Stratosphere-troposphere coupling in the Southern Hemisphere, J. Atmos. Sci., 62, 708-715, 2005. 